\title{
Experimental pathogenicity of four opportunist Fusarium species in a murine model
}

\author{
E. MAYAYO, I. PUJOL* and J. GUARRO† \\ Servei Patologia, Hospital Universitari de Tarragona Joan XXIII, * Laboratori de Microbiologia, Hospital \\ Universitari de Sant Joan de Reus and † Unitat de Microbiologia, Facultat de Medicina, Universitat Rovira $i$ \\ Virgili, 43201 Reus, Tarragona, Spain
}

\begin{abstract}
A murine model with immunocompetent animals was used in a comparative study of experimental pathogenicity of 13 isolates belonging to the four most frequent pathogenic species of Fusarium in man $(F$ solani, $F$. oxysporum, $F$ verticillioides and $F$. proliferatum). Inocula of $5 \times 10^{6}$ conidia/mouse of each isolate of $F$ usarium were injected into a lateral vein of the tail of the mice to produce a systemic infection. $F$. solani was the most virulent species; the five strains of this species assayed caused the death of all the animals tested in $<19$ days. The other species of Fusarium were not virulent in this model. The organs mainly affected by $F$. solani were the kidneys and the heart. These findings correlate with the clinical evidence and demonstrate that there is a high risk associated with infection by $F$. solani, especially for immunocompromised patients.
\end{abstract}

\section{Introduction}

In recent years, filamentous fungi have been implicated in an increasing number of opportunist infections in immunocompromised patients [1]. The genus Fusarium is particularly important and $F$. solani is the species that most frequently causes severe disseminated infections in man. Other infectious species, encountered to a lesser extent, are $F$. oxysporum and $F$. verticillioides. $F$. proliferatum has also caused a small number of cases. These infections have a high mortality and as yet there is no effective treatment against them. The invitro susceptibility of Fusarium spp. to the available antifungal drugs does not allow the prediction of any adequate treatment [2]. The pathogenicity of $F$. solani in mice has also been clearly demonstrated $[3,4]$. Nevertheless, why this species is the most frequent in these processes is unknown. It is probably the most prevalent or the most virulent, or both, and the infections produced by other species are more easily controlled by the host defences and are not disseminated.

This report describes a comparative study of the pathogenicity of the four most important species of Fusarium in human diseases in a murine model [3].

Received 12 Dec. 1997; revised version received 27 July 1998; accepted 29 July 1998.

Corresponding author: Professor J. Guarro (e-mail: umb@ fmcs.urv.es).

\section{Materials and methods}

\section{Test isolates}

Thirteen isolates of Fusarium spp. (10 from clinical sources and 3 from environmental sources) were used (Table 1): $F$. solani (5), F. oxysporum (5), F. verticillioides (2) and $F$. proliferatum (1). The fungi were stored on potato carrot agar (PCA) slants covered by mineral oil and as a suspension in water at room temperature.

\section{Preparation of inoculum}

Strains were subcultured on to PCA slants and incubated at $30^{\circ} \mathrm{C}$ for 15 days. The inoculum was prepared by flooding the surface of the agar slant with distilled water, scraping the sporulating mycelium with a teasing needle and drawing up the resultant suspensions with a sterile pasteur pipette. The suspensions were then filtered once through sterile gauze to remove hyphae and a suspension with $>90 \%$ conidia was obtained. The conidial suspensions were counted with a haemacytometer and counts were verified by serial dilutions on PCA plates which were incubated at $30^{\circ} \mathrm{C}$ for $72 \mathrm{~h}$. The suspensions were diluted in sterile $\mathrm{NaCl} 0.9 \%$ to produce the final inoculum of $2.5 \times 10^{7}$ conidia $/ \mathrm{ml}$.

\section{Animals}

$0 \mathrm{~F}_{1}$ male mice (Griffa, Barcelona, Spain) weighing $30 \mathrm{~g}$ were used. Mice were housed $10 /$ box in standard 
Table 1. Isolates of Fusarium studied and survival of immunocompetent mice within 30 days

\begin{tabular}{|c|c|c|c|c|}
\hline \multirow[b]{2}{*}{ Strain } & & \multirow[b]{2}{*}{ Origin } & \multicolumn{2}{|c|}{ Survival (days) } \\
\hline & & & Median & Range \\
\hline F solani & FMR 4927 & Skin & 7 & $2-19$ \\
\hline F. solani & FMR 4928 & Subcutaneous abscess & 2 & $2-16$ \\
\hline F. solani & FMR 4931 & Skin & 9 & $1-13$ \\
\hline F. solani & FMR 5207 & Skin & 2 & $1-14$ \\
\hline F. solani & $91-798$ & Blood & 14 & $11-18$ \\
\hline F. oxysporum & FMR 5203 & Blood & $>30$ & $1->30$ \\
\hline F. oxysporum & $7526 / \mathrm{V}$ & Nail & $>30$ & $>30$ \\
\hline F. oxysporum & $117-\mathrm{F}$ & Skin & $>30$ & $>30$ \\
\hline F. oxysporum & CBS 620.87 & Kernel of Hordeum vulgare & $>30$ & $>30$ \\
\hline F. oxysporum & FMR 4396 & Soil & $>30$ & $2->30$ \\
\hline F. verticillioides & $91-1478$ & Blood & $>30$ & $>30$ \\
\hline F. verticillioides & FMR 4393 & Soil & $>30$ & $3->30$ \\
\hline F. proliferatum & $90-1007$ & Lung & $>30$ & $>30$ \\
\hline
\end{tabular}

FMR, Faculty of Medicine of Reus.

boxes with corn-cob bedding and given food and water ad libitum.

\section{Infection model}

Inoculum suspensions $\left(200 \mu \mathrm{l}\right.$ volumes of $5 \times 10^{6}$ conidia/mouse) of each fungal strain were injected into the lateral tail veins of groups of 20 mice. Mortality was recorded daily for 30 days after inoculation.

\section{Histopathology}

Representative formalin-fixed portions of kidneys, liver, spleen, lungs, eyes, heart and brain obtained from animals at autopsy were stained with haematoxylin and eosin, PAS and Grocott (methenamine silver).

\section{Results}

Table 1 summarises the results obtained from inoculating immunocompetent mice with four species of Fusarium spp. F solani was the most virulent species; the five strains tested caused the death of all the animals within the study period (no animal survived longer than 19 days). The other three species caused a significantly lower degree of mortality varying from 0 to $40 \%$ of the animals tested. Three strains of $F$. oxysporum, one of $F$ verticillioides and the single strain of $F$. proliferatum did not cause the death of any animal.
The distribution of affected organs in mice infected by $F$ solani is shown in Table 2 . The organs that were mainly affected were the kidneys (in all the animals tested) and the heart (in $c .50 \%$ of the animals tested). These organs showed lesions made up of necrotic material with polymorphonuclear cells and variable amounts of branched, non-pigmented hyphae. Angioinvasion and thrombosis were also observed frequently. Granulomatous inflammation was never observed in the tissue sections of the infected organs.

Kidneys were always affected bilaterally with similar lesions in each organ. The changes induced by the five strains of $F$ solani tested were progressive. The parenchyma was affected in proportion to the duration of the fungal infections. The infectious fungal elements were observed, in some glomeruli and tubules of the cortical zone and with practically no inflammatory response, between 1 and 2 days after inoculation. After 4 days, a high degree of infection was noticed with the presence of micro-abscesses, a certain amount of parenchymal destruction and a greater abundance of hyphae. The inflammatory response was weak. After 7 days, the presence of fungal elements was more evident at the level of the pelvis and the parenchymatous foci disappeared without granuloma being detected. In those mice that survived longer than 11 days, both kidney pelvises were dramatically invaded by hyphae; they were clearly dilated and macroscopically white. An inflammatory response surrounding the affected area was

Table 2. Distribution of affected organs in mice infected by $F$. solani that died during the experiment

\begin{tabular}{|c|c|c|c|c|c|c|c|c|}
\hline \multirow[b]{2}{*}{ Strain no. } & \multirow{2}{*}{$\begin{array}{l}\text { Number of } \\
\text { animals } \\
\text { tested }\end{array}$} & \multicolumn{7}{|c|}{ Number of animals affected } \\
\hline & & Kidneys & Lungs & Heart & Brain & Eyes & Liver & Spleen \\
\hline FMR 4927 & 20 & 20 & 6 & 12 & 10 & 8 & 4 & 0 \\
\hline FMR 4928 & 20 & 20 & 10 & 12 & 4 & 4 & 2 & 2 \\
\hline FMR 4931 & 20 & 20 & 8 & 12 & 4 & 8 & 4 & 4 \\
\hline FMR 5207 & 20 & 20 & 4 & 10 & 4 & 6 & 2 & 0 \\
\hline $91-798$ & 20 & 20 & 5 & 10 & 4 & 8 & 2 & 2 \\
\hline
\end{tabular}

FMR, Faculty of Medicine of Reus. 
observed. There was also a considerable degree of myocardial involvement which was progressive at first, but which soon decreased and finally almost disappeared. The fungus invasion of the myocardium suddenly decreased at about the same time as a massive involvement of the renal pelvis was observed.

In decreasing order the other organs affected were the lungs, eyes, brains, liver and spleen, but in these cases the number of animals affected was closely related to the strain. Visible skin lesions were not seen.

\section{Discussion}

The murine model described by Legrand et al. [3] has proved to be very useful in comparing the pathogenicity of the most frequent species of Fusarium causing fungal infection in man. The four species tested (not always easily differentiated from each other when derived from clinical sources [2]) showed different degrees of pathogenicity. In the present study, $F$. solani was practically the only species that was highly virulent in immunocompetent mice. Although the five strains tested caused the death of all animals, variable pathogenicity over the period of the experiment was observed among them; the clinical isolate from a blood culture, with a survival median of 2 weeks, was the least virulent. The finding that $F$. solani was more pathogenic than the other species in this model is in agreement with the clinical evidence, because most disseminated fusarial infections are caused by $F$. solani.

In a recent report on disseminated Fusarium infections it was noted that 27 of the 83 cases reported were caused by $F$ solani, 12 by $F$ verticillioides and 11 by $F$. oxysporum [2]. Unfortunately, almost all of the strains belonging to these three species were resistant in vitro to all the antifungals tested [5]. However, $F$. solani strains were most resistant to amphotericin B, the antifungal agent most widely used in these infections. The mean MIC of amphotericin B against F. solani in a microdilution method was $3.47 \mathrm{mg} / \mathrm{L}$, while those of $F$. oxysporum and $F$. verticillioides were $2.13 \mathrm{mg} / \mathrm{L}$ and $1.98 \mathrm{mg} / \mathrm{L}$, respectively [5]. Similarly, the efficacy of the treatment regimens assessed in vivo is questionable. Of greater importance in immunosuppressed patients is the recovery of the neutrophil count, which appears to be essential for clinical resolution. In only one of the 27 cases of resolved $F$. infection did the neutrophil count not recover [6]. This was the only case in which a patient survived disseminated infection despite severe immunosuppression and persistent granulocytopenia. The patient underwent a bone marrow transplant and received amphotericin B, rifampicin and granulocyte transfusions. However, in this case the causative agent was $F$. proliferatum, a species that did not cause the death of any animal in the present study. In another recent case of fungaemia caused by a Fusarium sp. the infection responded to the oral triazole SCH 39304, despite progressive neutropenia, but in this case the species was $F$ oxysporum [7], which was also less virulent than $F$. solani in the present study. A recently reported infection caused by $F$. oxysporum in an HIVinfected patient with a port-a-cath was treated successfully with liposomal amphotericin B [8].

In all the animals infected by $F$. solani, the kidneys and heart were the most frequently affected organs. This was also observed by Legrand et al. [3] and it is in agreement with the results of previous studies where other fungi were assayed - such as Aphanoascus spp., the causative agents of rare superficial infections in man [9] and Scedosporium prolificans, an emerging agent of severe invasive infections [10]. However, brain involvement was noticed with the latter fungus. Involvement of the brain and eye (as much in intra-ocular structures as in neighbouring muscles) was also observed in the present study. Keratitis is a common type of infection caused by $F$. solani in immunocompetent individuals. It is relatively frequent and is distributed worldwide [11-17]. It mainly follows trauma, nail scratches, ocular surgery or complications caused by contact lens wear [18]. In neutropenic patients with disseminated fusarial infections, skin lesions are found in about $75 \%$ of individuals [2]. However, no visible cutaneous manifestations were observed in the present study. This is probably explained by the fact that the test animals were not immunocompromised. The experimental study performed by Legrand et al. [3] did not report skin lesions in neutropenic mice.

We thank Dr F. Odds (Janssen Research Foundation) for critical review of this manuscript and Drs Alonso, Ballester and Rinaldi, and the Curator of CBS (the Netherlands) for supplying strains for the study.

\section{References}

1. Guarro J, de Hoog GS, Figueras MJ, Gené J. Rare opportunistic fungi. In: de Hoog GS, Guarro J (eds) Atlas of clinical fungi. Baarn, Centraalbureau voor Schimmelcultures. 1995: 241-675.

2. Guarro J, Gené J. Opportunistic fusarial infections in humans. Eur J Clin Microbiol Infect Dis 1995; 14: 741-754.

3. Legrand C, Anaissie E, Hashem R, Nelson P, Bodey GP, Ro J. Experimental fusarial hyalohyphomycosis in a murine model. $J$ Infect Dis 1991; 164: 944-948.

4. Anaissie EJ, Hachem R, Legrand C, Legenne P, Nelson P, Bodey GP. Lack of activity of amphotericin B in systemic murine fusarial infection. $J$ Infect Dis 1992; 165: 1155-1157.

5. Pujol I, Guarro J, Gené J, Sala J. In-vitro antifungal susceptibility of clinical and environmental Fusarium spp. strains. J Antimicrob Chemother 1997; 39: 163-167.

6. Barrios NJ, Kirkpatrick DV, Murciano A, Stine K, Van Dyke RB, Humbert JR. Successful treatment of disseminated Fusarium infection in an immunocompromised child. $A m J$ Pediatr Hematol Oncol 1990; 12: 319-324.

7. Raad I, Hachem R. Treatment of central venous catheterrelated fungemia due to Fusarium oxysporum. Clin Infect Dis 1995; 20: 709-711.

8. Eljaschewitsch J, Sandfort J, Tintelnot K, Horbach I, Ruf B. Port-a-cath-related Fusarium oxysporum infection in an HIVinfected patient: treatment with liposomal amphotericin B. Mycoses 1996; 39: 115-119.

9. Cano J, Mayayo E, Guarro J. Experimental pathogenicity of 
Aphanoascus spp. Mycoses 1990; 33: 41-45.

10. Cano J, Guarro J, Mayayo E, Fernández-Ballart J. Experimental infection with Scedosporium inflatum. J Med Vet Mycol 1992; 30: $413-420$.

11. Foster CS. Fungal keratitis. Infect Dis Clin North Am 1992; 6: $851-857$.

12. Liesegang TJ, Forster RK. Spectrum of microbial keratitis in South Florida. Am J Ophthalmol 1980; 90: 38-47.

13. Forster RK, Rebell G. The diagnosis and management of keratomycosis, I. Cause and diagnosis. Arch Ophthalmol 1975; 93: 975-978.

14. Gugnani HC, Talwar RS, Njsoku-Obi ANV, Kodilinye HC.
Mycotic keratitis in Nigeria. A study of 21 cases. $\mathrm{Br} J$ Ophthalmol 1976; 60: 607-613.

15. Ishibashi Y. [Keratomycosis in Japan reported from 1976 to 1980.] Nippon Ganka Gakkai Zasshi 1982; 86: 651-656.

16. Jones DB, Sexton RR, Rebell G. Mycotic keratitis in south Florida, a review of 39 cases. Trans Ophthalmol Soc UK 1969; 89: $781-797$.

17. Polack FM, Kaufman HE, Newmark E. Keratomycosis. Medical and surgical treatment. Arch Opthalmol 1971; 85: 410-416.

18. Strelow SA, Kent HD, Eagle RC, Cohen EJ. A case of contact lens related Fusarium solani keratitis. CLA Op $J$ 1992; 18: $125-127$. 